\title{
Validitas dan efektivitas prototipe buku ajar fisika dasar reflektif-integratif berbasis problem solving untuk meningkatkan pengetahuan metakognisi
}

\author{
Muhammad Asy'ari *, Samsun Hidayat, Muhali Muhali \\ Universitas Pendidikan Mandalika. Jalan Pemuda No.59A, Dasan Agung Baru, Kota Mataram, Nusa \\ Tenggara Barat 83125, Indonesia \\ * Coressponding Author. E-mail: muhammadasyari@ikipmataram.ac.id \\ Received: 12 September 2019; Revised: 23 September 2019; Accepted: 10 October 2019
}

\begin{abstract}
Abstrak
Penelitian ini bertujuan menghasilkan prototipe buku ajar fisika dasar reflektif-integratif berbasis problem solving yang valid dan efektif untuk meningkatkan pengetahuan metakognisi peserta didik. Desain penelitian ini adalah eksperimen semu menggunakan one group pretest-posttest design, dengan sampel 25 peserta didik program studi pendidikan fisika FPMIPA IKIP Mataram. Instrumen penelitian ini menggunakan lembar validasi untuk mengukur validitas produk, dan tes berbentuk essay yang mengukur efektivitas produk untuk meningkatkan pengetahuan metakognisi peserta didik. Data dan analisis yang digunakan yaitu: (1) validitas produk dilakukan oleh 2 (dua) ahli yang berkompeten dan dianalisis secara deskriptif, dan (2) efektivitas produk diukur setelah pembelajaran dan dianalisis secara deskriptif menggunakan persamaan $n$-gain, dan secara statistik dengan paired samples test. Hasil penelitian menunjukkan prototipe buku ajar fisika dasar reflektif-integratif berbasis problem solving valid $(3,38)$ dan reliabel $(0,97)$, sedangkan pengetahuan metakognisi meliputi pengetahuan deklaratif $(n$-gain $=0,58)$, pengetahuan prosedural $(n$-gain $=0,53)$, dan pengetahuan kondisional ( $n$-gain $=0,56$ ) dinyatakan meningkat setelah pembelajaran dengan kategori sedang. Hasil uji statistik menunjukkan prototipe buku ajar fisika dasar reflektif-integratif berbasis problem solving berpengaruh signifikan $(\mathrm{p}<0,05)$ terhadap pengetahuan metakognisi peserta didik. Dengan demikian, prototipe buku ajar fisika dasar reflektif-integratif berbasis problem solving valid dan efektif untuk meningkatkan pengetahuan metakognisi peserta didik.
\end{abstract}

Kata Kunci: validitas, efektivitas, reflektif-integratif, pengetahuan deklaratif, pengetahuan prosedural, dan pengetahuan kondisional.

\section{Validity and effectiveness of reflective-integrative basic physics textbook prototype based on problem solving to improve metacognition knowledge}

\begin{abstract}
This study aimed at producing a valid and effective reflective-integrative basic physics textbook prototype based on problem solving in order to improve students' metacognitive knowledge at university level. The design was quasi experiment with one group pretest-posttest design, which involved 25 students of FPMIPA, IKIP Mataram. Instruments of the study were a validation sheet to measure product validity and an essay test to measure effectiveness of the product in attempt to improve students' metacognitive knowledge. Data and its analysis were conducted through: (1) two experts' descriptive judgements on the validity of the text book and (2) descriptive analysis on product effectiveness analyzed after learning session by using $n$-gain equation and statistical analysis using paired sample test. Results show that the text book prototype was valid (3.38) and reliable (0.97), while metacognitive knowledge that covered declarative knowledge (n-gain= $0.58)$, procedural knowledge $(n$-gain $=0.53)$, and conditional knowledge $(n$-gain $=0.56)$ were found improved at medium level after learning conducted. Statistical test result shows that the text book protype had significant effect $(p<0.05)$ towards students' metacognitive knowledge. Therefore, the reflectiveintegrative basic physics textbook prototype based on problem solving was found valid and effective in improving students' metacognitive knowledge at university level.
\end{abstract}

Keywords: validity, effectiveness, reflective-integrative, declarative knowledge, procedural knowledge, conditional knowledge

How to Cite: Asy'ari, M., Hidayat, S., \& Muhali, M. (2019). Validitas dan efektivitas prototipe buku ajar fisika dasar reflektif-integratif berbasis problem solving untuk meningkatkan pengetahuan metakognisi. Jurnal Inovasi Pendidikan IPA, 5(2), 205-215. doi:https://doi.org/10.21831/jipi.v5i2.27089

doi https://doi.org/10.21831/jipi.v5i2.27089 


\section{PENDAHULUAN}

Fisika merupakan ilmu yang dikategorikan bersifat induktif dengan menghasilkan produk berupa pengetahuan yang meliputi konsep, fakta, prinsip, teori, dan hukum (Sutarto \& Indrawati, 2010). Produk-produk tersebut hendaknya dikembangkan sendiri oleh peserta didik sesuai dengan kesiapan kognitifnya masing-masing, sehingga bernilai tambah (Suyono \& Hariyanto, 2011). Kedua pernyataan tersebut mengindikasikan bahwa dalam pembelajaran fisika peserta didik dapat mengembangkan sendiri pengetahuannya dalam berpikir dan bersikap ilmiah untuk menyelesaikan masalah.

Metakognisi sebagai keterampilan abad 21 sangat penting dibelajarkan untuk membentuk peserta didik mandiri yang merupakan tujuan akhir pembelajaran (National Research Council, 2012). Oleh karena itu, dalam pembelajaran fisika metakognisi sebagai produk terkait dengan informasi yang dibutuhkan, bagaimana menggunakan informasi, dan kapan menggunakan dan mengimplementasikan informasi atau pengetahuan tersebut dalam pembelajaran, telah menjadi isu yang sangat penting di dalam dunia pendidikan (Zohar \& Dori, 2011). Metakognisi dalam pembelajaran dianjurkan menjadi tujuan kurikulum sekolah pada semua disiplin ilmu (Bransford et al., 2000). Metakognisi juga merupakan komponen yang sangat penting dalam pembelajaran sains untuk semua usia (Zohar \& Dori, 2011). Metakognisi harus dilakukan sebelum, selama, dan setelah pengajaran (Wen, 2012). Metakognisi memiliki dua komponen (Schraw, Olafson, Weibel, \& Sewing, 2012; Veenman, 2012) yaitu pengetahuan metakognisi dan kesadaran metakognisi. Pengetahuan metakognisi mencakup tiga pengetahuan yaitu deklaratif, prosedural, dan kondisional (Schraw et al., 2012), sedangkan kesadaran metakognisi terdiri dari perencanaan, pemeriksaan, dan evaluasi (Schraw, Crippen, \& Hartley, 2006; Schraw et al., 2012; Schraw \& Moshman, 1995), pemeriksaan (Pressley \& Harris, 2009), strategi manajemen informasi dan perbaikan strategi (Schraw et al., 2012). Metakognisi menurut (Hacker, Bol, \& Keener, 2008) memiliki tiga komponen: (1) pengetahuan metakognisi (apakah seseorang mengetahui pengetahuannya), (2) keterampilan metakognisi (apa yang sedang dilakukannya), dan (3) pengalaman metakognisi (keadaan kognitif atau afektif seseorang). (Flavell, 1979) juga membagi komponen metakognisi menjadi tiga bagian yaitu: (1) pengetahuan dan keyakinan tentang kognisi; (2) monitoring kognisi; dan (3) regulasi kognisi.

Hasil penelitian menunjukkan bahwa $1 / 3$ keterampilan inovatif dipengaruhi faktor hereditas (Dyer, Gregersen, \& Christensen, 2011), artinya $2 / 3$ keterampilan-keterampilan inovatif diperoleh melalui serangkaian kegiatan pembelajaran yang dilakukan oleh peserta didik dengan baik. Komponen penting dalam pembelajaran, salah satunya adalah tersedianya buku ajar yang baik dalam menuntun peserta didik berpikir secara mandiri. Kriteria buku ajar yang baik menurut (Madsen, McKagan, Martinuk, Bell, \& Sayre, 2016) memuat prinsip eksperimen, discovery, inkuiri, dan problem solving, sehingga dapat memfasilitasi peserta didik untuk menghubungkan pengetahuan prosedural, faktual, konseptual dan metakognisi dalam memecahkan masalah pembelajaran.

Pemecahan masalah (problem solving) sebagai strategi memiliki 3 (tiga) langkah yaitu: (1) mendefinisikan permasalahan, (2) membuat formulasi opsi pemecahan masalah yang layak, dan (3) memilih solusi pemecahan masalah yang relevan (Adair, 2019). (Facione \& Gittens, 2015) menggunakan istilah IDEAS sebagai langkahlangkah pemecahan masalah kreatif dan pembuatan keputusan, yaitu identifikasi (identify) permasalahan dan menentukan prioritas, memperdalam (deepen) pemahaman dan menyediakan informasi yang relevan, menghitung (enumerate) opsi pemecahan dan antisipasi konsekuensi, menilai (assess) situasi dan membuat keputusan awal, dan meneliti secara cermat (scrutinize) proses pemecahan dan koreksi diri jika diperlukan. Lebih lanjut, (Nitko \& Brookhart, 2011) mengajukan istilah IDEAL yaitu mengidentifikasi (Identify) masalah, mendefinisikan (Define) dan menyajikan masalah, mencari (Explore) strategi pemecahan yang memungkinkan, implementasi (Act) berdasarkan strategi, dan meninjau kembali (Look back) dan mengevaluasi pengaruh. Problem solving sebagai kemampuan sangat penting untuk dimiliki dalam memecahkan masalah kehidupan nyata di masa mendatang (Tivani \& Paidi, 2016).

Langkah-langkah problem solving yang diintegrasikan dalam prototipe buku ajar fisika dasar reflektif-integratif dan diimplementasikan dalam pembelajaran/ujicoba mengadopsi langkah-langkah yang telah diuraikan sebelumnya yang terdiri atas: (1) mendefinisikan masalah, (2) mencatat kondisi, (3) merumuskan hipotesis, (4) mengelaborasi, dan (5) menguji ide-ide, dengan pengintegrasian proses-proses reflektif seperti 
konflik kognitif (Thomas, 2012), dan simulasi fenomena anomaly yang berkaitan erat dengan kehidupan rutin peserta didik (Mischel, 1971), yang dijadikan petunjuk bagi peserta didik dalam pembelajaran.

Problem solving memiliki salah satu karakteristik yaitu refleksi yang mendukung untuk membelajarkan keterampian berpikir peserta didik. Refleksi memiliki hubungan yang erat dengan kemampuan metakognisi peserta didik. (Thomas, 2012) menyatakan bahwa refleksi dan metakognisi memiliki kesamaan dalam penekanan pemahaman dan peningkatan proses dan hasil pembelajaran serta pemusatan perhatian peserta didik yang efektif. Hasil penelitian terkait pengguanaan buku ajar disampaikan (Hasanah, Gummah, \& Herayanti, 2018) yang menyatakan bahwa penggunaan handout berbasis pemecahan masalah dapat menjadi solusi alternatif dalam meningkatkan keterampilan berpikir peserta didik baik berpikir kritis maupun kreatif, tetapi secara spesifik hand-out tersebut lebih efektif untuk melatih berpikir kritis dari pada berpikir kreatif. Hal ini dikarenakan melalui handout peserta didik mendapatkan kesempatan untuk memecahkan permasalahan pembelajaran berdasarkan pengalaman sehari-hari. Hal ini tidak efektif untuk melatihkan kemampuan berpikir secara maksimal karena peserta didik memiliki kecenderungan untuk memecahkan masalah secara apa adanya tanpa melihat kembali kinerjanya (Sukaisih \& Muhali, 2014), sehingga refleksi perlu ditekankan kepada peserta didik agar memiliki pemahaman, dan peningkatan proses dan hasil pembelajaran, serta pemusatan perhatian peserta didik yang efektif (Thomas, 2012).

Yuliati et al. (2011) menyampaikan hal serupa bahwa peningkatan keterampilan berpikir kritis bagi peserta didik dapat dilakukan melalui pembelajaran hands on activities. Hasil penelitian ini menunjukkan bahwa terdapat beberapa indikator berpikir kritis yang belum dicapai secara optimal oleh peserta didik, yaitu: (1) kemampuan berhipotesis peserta didik mencapai nilai dengan rata-rata siklus I $(45,10)$, II $(56,86)$, dan III $(60,78)$, (2) kemampuan menganalisis peserta didik memperoleh nilai dengan rata-rata siklus I $(36,27)$, II $(37,25)$, dan III $(41,18)$, (3) kemampuan mengevaluasi peserta didik memperoleh nilai dengan rata-rata siklus I $(35,29)$, II $(35,29)$, dan III $(38,24)$, dan (4) menarik kesimpulan mencapai nilai dengan rata-rata siklus I $(37,25)$, II $(42,16)$, dan III $(48,04)$. Hasil ini sejalan dengan hasil belajar afektif pada indikator bertanya dan memberikan tanggapan, dengan perolehan nilai masing-masing pada siklus I (60,29 dan 35,29), II (63,24 dan 36,03), dan III $(68,38$ dan 41,18). Berdasarkan perolehan data tersebut maka pembelajaran hands on activities yang dilakukan oleh Yuliati et al. (2011) tidak mampu membentuk pengetahuan peserta didik secara maksimal, terutama pengetahuan deklaratif dan prosedural, oleh karena itu penting untuk dibelajarkan lebih optimal. Menurut Muhali (2018) untuk dapat membelajarkan pengetahuan tersebut dilakukan beberapa upaya yaitu dengan strategi konflik kognitif, penyajian fenomena anomaly, internalisasi, dan melalui penyajian fenomena baru yang masih terkait. Metakognisi disinyalir dapat dibelajarkan melalui integrasi keterampilan proses sains dalam pembelajaran (Astuti \& Setiawan, 2013).

Lebih lanjut Taqiyyah et al. (2017) menemukan bahwa penggunaan bahan ajar sains yang berbasis metakognitif dapat memberikan peningkatan pada kemampuan pemecahan masalah peserta didik. Hasil yang diperoleh dari penelitian Taqiyyah et al. (2017), kemampuan pemecahan masalah pada indikator mengecek kembali oleh peserta didik memperoleh hasil paling rendah dibandingkan indikator yang lain, dengan pencapaian $66,67 \%$ (kelas eksperimen) dan $42,67 \%$ (kelas kontrol). Kesulitan yang dihadapi peserta didik sesuai hasil penelitian tersebut sejalan dengan penelitian Lester, Garofalo, \& Kroll (1989) bahwa peserta didik tidak dapat melakukan verifikasi pemecahan masalah dengan baik. Oleh karena itu, Yimer dan Ellerton (2010) menekankan proses refleksi pada setiap langkah pembelajaran dan refleksi secara menyeluruh pada keseluruhan langkah-langkah pemecahan masalah. Di pihak lain, (Puspita, 2019) mengembangkan modul keterampilan proses sains dan menemukan bahwa modul yang dikembangkan layak dan menarik bagi peserta didik untuk digunakan dalam pembelajaran. Modul yang dikembangkan (Puspita, 2019) masih terbatas hanya pada hasil penilaian validator dan penilaian responden dalam hal desain produk, tidak secara eksplisit untuk pencapaian hasil belajar peserta didik padahal hasil belajar sebagai tuntutan kurikulum.

Berdasarkan uraian tersebut, prototype buku ajar fisika dasar dengan menekankan pada pengintegrasian proses refleksi dalam pemecahan masalah bagi peserta didik sangat penting untuk dikembangkan agar pengetahuan (deklaratif, prosedural, dan kondisional) secara utuh dapat dibelajarkan dengan baik. Produk yang dikembangakn merupakan sebuah prototype buku ajar pada mata 
kuliah fisika dasar yang menekankan proses reflektif-integratif berbasis problem solving dengan harapan peserta didik memiliki pengetahuan metakognisi yang lebih baik, mengingat hasil penelitian yang telah diuraikan sebelumnya belum secara eksplisit menghasilkan produk berupa buku ajar yang yang terbukti valid dan efektif untuk meningkatkan atau melatihkan pengetahuan metakognisi peserta didik. Penelitian ini bertujuan menghasilkan prototipe buku ajar mata kuliah fisika dasar yang menekankan pada proses reflektif-integratif berbasis problem solving yang valid dan efektif untuk meningkatkan pengetahuan metakognisi peserta didik yang meliputi 3 (tiga) aspek pengetahuan yaitu deklaratif, prosedural, dan kondisional. Pengintegrasian prosesproses reflektif seperti penyajian konflik kognitif, data anomaly, dan pendalaman pemahaman melalui penyajian permasalahan lanjutan yang masih terkait dengan materi ajar dalam prototype buku ajar yang dikembangkan diharapkan mampu mengembangkan motivasi belajar sehingga memfasilitasi peserta didik menggunakan proses kognitif tinggi untuk dapat menyerap dan mengkonstruksi pengetahuan secara mandiri. Pernyataan tersebut sejalan dengan rekomendasi Asy'ari, Ikhsan, \& Muhali (2019) bahwa penting untuk melakukan pembelajaran dengan pengintegrasian strategi-strategi belajar seperti konflik kognitif, penyajian permasalahan non-rutin, dan penilaian berbasis kinerja/portofolio.

\section{METODE}

Jenis penelitian ini adalah eksperimen semu dengan menggunakan rancangan one group pretest-posttest design seperti pada Gambar 1. Desain penelitian ini digunakan untuk melihat efektivitas prototype buku ajar fisika dasar reflektif-integratif berbasis problem solving yang merupakan desain produk pengembangan yang dilakukan oleh Asy'ari dan Hidayat (2019) Sebelum produk tersebut diimplementasikan dalam pembelajaran maka sebagai langkah awal dilakukan validasi oleh tim validator yang berkompeten.

\begin{tabular}{ccc}
\hline $\mathrm{O}_{1}$ & $\mathrm{X}$ & $\mathrm{O}_{2}$ \\
\hline Pretest & Treatment & Posttest \\
\hline
\end{tabular}

Gambar 1. Rancangan Penelitian dengan one group pretest-posttest design (Fraenkel, Wallen, \& Hyun, 2012).

Di mana: $O_{1}=$ data pengetahuan metakognisi peserta didik sebelum pembelajaran, $\mathrm{O}_{2}=$ data pengetahuan metakognisi peserta didik setelah pembelajaran, dan $X=$ perlakuan dengan menerapkan produk prototype buku ajar fisika dasar reflektif-integratif dalam pembelajaran.

Subjek yang digunakan pada peelitian ini sebanyak 25 orang peserta didik pada program studi pendidikan fisika FPMIPA IKIP Mataram yang memprogramkan dan mengikuti perkuliahan fisika dasar pada tahun akademik 2018/2019. Instrumen penelitian ini berupa lembar validasi dan tes berupa soal essay. Instrumen lembar validasi digunakan untuk menilai validitas prototype buku ajar, sedangkan instrumen tes digunakan untuk mengukur efektivitas prototype buku ajar dalam meningkatkan pengetahuan metakognisi peserta didik. Instrumen tes yang digunakan adalah instrumen pengetahuan metakognisi yang telah dikembangkan oleh (Asy'ari, Ikhsan, \& Muhali, 2018; Asy'ari et al., 2019) dan telah divalidasi dengan kriteria valid (Pearson correlation $>\mathrm{t}_{\text {tabel }}$ ) dan reliabel (Cronbach's alpha $=0,94)$ untuk mengevaluasi pengetahuan metakognisi.

Penelitian ini menghasilkan data berupa validitas dan efektivitas prototype buku ajar fisika dasar reflektif-integratif berbasis problem solving untuk meningkatkan pengetahuan metakognisi peserta didik. Teknik pengumpulan data yaitu: (1) teknik validasi untuk memperoleh data validitas produk, dilakukan oleh 2 (dua) orang ahli/akademisi dibidang pendidikan fisika dengan memberikan penilaian menggunakan lembar validasi yang telah disiapkan peneliti, (2) teknik tes untuk mendapatkan data efektivitas produk untuk meningkatkan pengetahuan metakognisi, dilakukan sebelum dan setelah pembelajaran menggunakan produk prototype buku ajar fisika dasar reflektif-integratif berbasis problem solving pada materi fluida yang dikembangkan untuk meningkatkan kemampuan metakognisi mahasaiswa calon guru.

Analisis data dilakukan melalui 2 (dua) cara yaitu secara deskriptif dan statistik. Data validitas produk dianalisis secara deskriptif, sedangkan data efektivitas produk dianalisis secara deskriptif menggunakan persamaam n-gain dan secara statistik menggunakan paired t-test.

\section{Validitas Prototype Buku Ajar Fisika Dasar Reflektif-Integratif Berbasis Problem Solving}

Validasi buku ajar pada penelitian ini meliputi 2 (dua) komponen antara lain: (1) validitas isi (content validity), dan (2) validitas konstruk (construct validity) (Nieveen, 1999). Prototype buku ajar fisika dasar reflektifintegratif berbasis problem solving divalidasi oleh 2 (dua) orang ahli yang memiliki kompetensi 
di bidang pendidikan fisika. Perbaikan atau revisi produk prototype buku ajar fisika dasar reflektifintegratif berbasis problem solving dilakukan sesuai saran dan masukan dari para validator. Penilaian validitas prototype buku ajar fisika dasar reflektif-integratif berbasis problem solving meggunakan 4 (empat) skala penilaian dan kategori yaitu, $1=$ sangat kurang, $2=$ kurang valid, 3 $=$ valid, dan $4=$ sangat valid. Skor yang diperoleh dari penilaian ahli terhadap produk tersebut dikonversi menjadi data kualitatif skala 4 (Ratumanan \& Laurens, 2006) dengan kriteria pada Tabel 1.

Tabel 1. Kriteria Perangkat Pembelajaran

\begin{tabular}{cc}
\hline Interval Nilai & Kriteria \\
\hline$>3,6$ & Sangat Valid \\
$2,8-3,6$ & Valid \\
$1,9-2,7$ & Tidak Valid \\
$1,0-1,8$ & Sangat Tidak Valid \\
\hline
\end{tabular}

Rata-rata nilai validitas dan realibilitas model dan perangkat pendukung model pembelajaran diperoleh dari nilai masing-masing validator. Prototype buku ajar dikatakan realibel apabila mencapai nilai percentage agreement sebesar $\geq 75 \%$, atau sebanyak $75 \%$ dari skor ratarata nilai oleh validator memiliki kategori valid. Realibilitas perangkat pembelajaran didapatkan melalui hasil perhitungan menggunakan persamaan percentage agreement (Emmer \& Millett dalam Borich, 1994) sebagai berikut.

Percentage Agreement $=100\left(1-\frac{A-B}{A+B}\right)$

Dengan: $A=$ frekuensi tingkah-laku yang diamati pengamat dengan memberikan frekuensi tinggi, $B=$ frekuensi tingkah-laku yang diamati pengamat lain dengan memberikan frekuensi rendah.

\section{Keefektifan Prototype Buku Ajar Fisika Dasar Reflektif-Integratif Berbasis Problem Solving}

Tabel 2. Kriteria Pengetahuan Metakognisi (K)

\begin{tabular}{cc}
\hline Predikat & Nilai \\
\hline Sangat Baik & $3.33<\mathrm{K} \leq 4$ \\
Baik & $2.33<\mathrm{K} \leq 3.33$ \\
Cukup & $1.33<\mathrm{K} \leq 2.33$ \\
Rendah & $\mathrm{K} \leq 1.33$ \\
\hline
\end{tabular}

Keefektifan prototype buku ajar fisika dasar reflektif-integratif berbasis problem solving terhadap pengetahuan metakognisi dievaluasi setelah implementasi pembelajaran. Skor yang diperoleh dianalisis dan dikategorisasi ke dalam 4 (empat) kriteria seperti pada Tabel 2 (Asy'ari et al., 2019).
Analisis peningkatan kemampuan metakognisi peserta didik dilakukan dengan uji paired samples test pada data pretest dan posttest dengan bantuan softwere IBM SPSS Statistics 23, dan persamaan $n$-gain sebagai berikut (Hake, 1999).

$n-$ gain $=\frac{(\text { Skor posttest }- \text { Skor pretest })}{(\text { Skor maximum }- \text { Skor pretest })}$

Nilai $N$-gain yang didapatkan selanjutnya dikonversi ke dalam kategori seperti pada Tabel 3.

Tabel 3. Kriteria Perubahan Skor ( $N$-gain) Peserta Didik Sebelum dan Sesudah Pembelajaran.

\begin{tabular}{cc}
\hline Rentang Skor & Keterangan \\
\hline$>0,70$ & Tinggi \\
$0,30-0,70$ & Sedang \\
$<0,30$ & Rendah \\
\hline
\end{tabular}

\section{HASIL DAN PEMBAHASAN}

\section{Validitas prototype buku ajar fisika dasar reflektif-integratif berbasis problem solving}

Prototype buku ajar fisika dasar reflektifintegratif berbasis problem solving penggunaannya sebagai pendukung pada pelaksanaan kegiatan pembelajaran peserta didik. Produk tersebut terlebih dahulu divalidasi oleh validator untuk mengetahui mutu berdasarkan kebenaran isi atau konten, organisasi penyajian baik konten maupun instruksional, dan aspek kebahasaan yang digunakan dalam penyajian materi pada buku ajar. Validitas produk terdiri dari validitas secara isi (content validity), dan validitas secara konstruk (construct validity). Validitas isi meliput semua komponen penyusun prototype buku ajar fisika dasar reflektif-integratif berbasis problem solving yang didasarkan atas keperluan (needs) dan tingkatan keilmuan atau pengetahuan (state of the art knowledgement) sesuai hasil analisis kurikulum yang berlaku, analisis peserta didik dan analisis konsep atau materi yang telah dilaksanakan pada Program Studi Pendidikan Fisika IKIP Mataram. Validitas konstruk diartikan bahwa semua komponen penyusun buku ajar harus secara konsisten dan berkaitan antara satu komponen dengan komponen lainnya. Unsur validitas isi dan konstruk yang divalidasi dari prototype buku ajar meliputi komponen-komponen penyusun prototype buku ajar fisika dasar reflektif-integratif berbasis problem solving. Nilai rata-rata penilaian validator terhadap semua aspek prototype buku ajar fisika dasar reflektifintegratif berbasis problem solving yang dikembangkan seperti pada Tabel 4. 
Tabel 4. Hasil Validasi Prototype Buku Ajar Fisika Dasar Reflektif-Integratif Berbasis Problem Solving

\begin{tabular}{lrcc}
\hline \multicolumn{3}{c}{ Validitas } & \multirow{2}{*}{ Reliabilitas } \\
\cline { 1 - 3 } \multicolumn{1}{c}{ Item } & Skor & Kategori & \\
Materi ajar & 3,59 & Valid & \\
Bahasa & 3,10 & Valid & \multirow{2}{*}{0,97} \\
Penyajian & 3,45 & Valid & \\
\cline { 1 - 3 } Rata-rata & 3,38 & Valid & \\
\hline
\end{tabular}

Berdasarkan Tabel 4, mengindikasikan bahwa penilaian validator secara keseluruhan terhadap komponen penyusun prototype buku ajar berkategori valid dengan rata-rata skor 3,38, dan reliabel dengan perolehan nilai persentase reliabilitas sebesar 0,97. Hasil ini memberikan gambaran bahwa prototype buku ajar fisika dasar reflektif-integratif berbasis problem solving dinyatakan valid dilihat dari komponen materi ajar/kebenaran isi, organi-sasi penyajian, dan aspek bahasa, sehingga dapat diimplementasikan dalam kegiatan pembelajaran.

Hasil penilaian pada Tabel 4 tersebut menunjukkan bahwa materi ajar dinyatakan sesuai dan memadai. Materi ajar dinyatakan sesuai artinya materi ajar yang dimuat telah sesuai dengan standar kompetensi (SK), kompetensi dasar (KD), dan tujuan pembelajaran, serta bebas dari miskonsepsi. Cain dan Evans (1990) menjelaskan bahwa materi yang disajikan tidak valid atau menimbulkan miskonsepsi menjadikan buku ajar tidak dapat berfungsi dengan sebenarnya sebagai sumber belajar, dan tidak berfungsi sebagai pendukung pembelajaran yang baik bagi peserta didik yang berimplikasi pada tidak tercapainya kualitas pembelajaran secara optimal. Materi ajar juga dinyatakan memadai artinya keluasan dan kedalaman materi sesuai dengan tingkat perkembangan peserta didik (materi tidak terlalu sedikit dan terlalu banyak), sehingga materi yang termuat dalam buku ajar benar-benar menggambarkan kompetensi yang diajarkan, dan dapat membantu peserta didik untuk memahami/ menguasai kompetensi dasar yang diajarkan.

Buku ajar dapat memenuhi peranan dan fungsinya sebagai sumber belajar bagi peserta didik dan dapat meningkatkan kualitas pembelajaran, maka penyajian materi ajar harus didukung oleh aktivitas atau tindakan yang dilakukan peserta didik sebagai bentuk kegiatan belajarnya dalam memahami materi tersebut, karena penyajian materi ajar tidak cukup hanya dengan penyajian pengetahuan saja tetapi yang lebih penting adalah penyajian materi yang dikombinasi pendekatan keterampilan proses (Adisendjaja,
2008). Hal tersebut dikarenakan keterampilan proses sains sebagai sarana mendasar bagi peserta didik dalam memperoleh pemahaman terhadap pengetahuan, dan mengembangkan keterampilan berpikirnya (Adisendjaja \& Romlah, 2007). Integrasi keterampilan proses sain dalam produk buku ajar fisika dasar reflektif-integratif terletak pada lembar kerja yang dijadikan sebagai suplemen prototipe buku ajar. Pengintegrasian komponen keterampilan proses sains dalam produk yang dikembangkan sejalan dengan penekanan prinsip konstruktivis yang menghendaki peserta didik dapat meng-konstruksi pengetahuan secara mandiri (Asy'ari \& Fitriani, 2017) dan menuntut partisipasi aktif peserta didik selama proses pembelajaran (Westwood, 2008). Lebih lanjut (Astuti \& Setiawan, 2013) menyatakan bahwa kegiatan yang menekankan pada keterampilan proses sains dapat memfasilitasi peserta didik untuk mengembangkan keterampilan berpikir tingkat tinggi termasuk pengetahuan metakognisi.

\section{Keefektifan Prototype Buku Ajar Fisika Dasar Reflektif-Integratif Berbasis Problem Solving}

Keefektifan prototype buku ajar yang dihasilkan dievaluasi setelah pembelajaran menggunakan buku ajar telah dinyatakan valid dan reliabel untuk meningkatkan pengetahuan metakognisi peserta didik melalui pemberian tes pengetahuan metakognisi. Distribusi data pengetahuan metakognisi peserta didik sebelum (pretest) dan setelah (posttest) pembelajaran selanjutnya dianalisis menggunakan one-sample Kolmogorov-Smirnov $Z$ dengan bantuan softwere IBM SPSS Statistics 23. Hasil uji distribusi data pretest dan posttest pengetahuan metakognisi peserta didik disajikan pada Tabel 5.

Hasil pengujian pada Tabel 5 menunjukkan nilai pretest dan posttest pengetahuan metakognisi peserta didik berdistribusi normal ( $\mathrm{p}$ $>0,05$ ), sehingga paired samples test digunakan untuk menganalisis dampak penggunaan prototype buku ajar fisika dasar reflektif-integratif berbasis problem solving setelah pembelajaran terhadap pengetahuan metakognisi peserta didik. Capaian pengetahuan metakognisi dan n-gain peserta didik berdasarkan 3 (tiga) indikator pengetahuan metakognisi pengetahuan deklaratif (DK), pengetahuan prosedural (PK), dan pengetahuan konsidional (CK) serta hasil uji paired samples test sebelum dan sesudah pembelajaran disajikan pada Tabel 6 . 
Jurnal Inovasi Pendidikan IPA, 5 (2), 2019 - 211

Muhammad Asy'ari, Samsun Hidayat, Muhali Muhali

Tabel 5. Normalitas Data Pretest dan Posttest Pengetahuan Metakognisi Peserta Didik

\begin{tabular}{ccccccc}
\hline \multirow{2}{*}{ Item } & \multirow{2}{*}{ Tes } & \multirow{2}{*}{$\mathrm{N}$} & \multicolumn{4}{c}{ Pengetahuan Metakognisi } \\
\cline { 4 - 7 } & & Mean & Std. Deviation & Asymp. Sig. (2-tailed) & Normalitas \\
\hline \multirow{2}{*}{ Pretest-posttest } & pre-test & 25 & 1.6688 & .11428 & .603 & ya \\
& post-test & 25 & 2.9608 & .10255 & .059 & ya \\
\hline
\end{tabular}

Tabel 6. Hasil Paired Samples Test Pre-test dan Post-test Pengetahuan Metakognisi Peserta Didik

\begin{tabular}{|c|c|c|c|c|c|c|c|}
\hline \multirow{2}{*}{ Scores } & \multicolumn{3}{|c|}{ Indikator Pengetahuan Metakognisi } & \multirow{2}{*}{$\mathrm{N}$} & \multirow{2}{*}{ Mean } & \multirow{2}{*}{ SD } & \multirow[b]{2}{*}{$\mathrm{p}$} \\
\hline & DK & PK & CK & & & & \\
\hline Pre-test & 1.65 & 1.70 & 1.65 & & 1.6688 & & \\
\hline Post-test & 3.02 & 2.91 & 2.96 & 25 & 2.9608 & .15294 & .000 \\
\hline n-gain & 0.58 & 0.53 & 0.56 & & & & \\
\hline
\end{tabular}

Tabel 6 menunjukkan bahwa pengetahuan metakognisi peserta didik berdasarkan nilai $n$ gain mengalami peningkatan pada setiap indikator. Nilai signifikansi pengetahuan metakognisi peserta didik setelah pembelajaran menggunakan prototype buku ajar fisika dasar reflektifintegratif berbasis problem solving adalah $\mathrm{p}<$ 0,05 (berkategori signifikan). Hasil tersebut menunjukkan dampak positif penggunaan prototype buku ajar fisika dasar reflektif-integratif berbasis problem solving terhadap pengetahuan metakognisi peserta didik.

Pengetahuan metakognisi peserta didik mengalami peningkatan signifikan $(\mathrm{p}<0,05)$ setelah pembelajaran menggunakan prototipe buku ajar fisika dasar reflektif-integratif berbasis problem solving di mana pengetahuan deklaratif $(\mathrm{n}$-gain $=0,58)$, pengetahuan prosedural $(\mathrm{n}$-gain $=$ 0,53 ), dan pengetahuan kondisional (n-gain= $0,56)$ peserta didik berkategori sedang. Hasil penelitian tersebut tidak terlepas dari integrasi model pembelajaran problem solving yang dijadikan sebagai model pembelajaran yang diimplementasikan dalam pembelajaran. (Taqiyyah et al., 2017) menyatakan pembelajaran yang berorientasi pada pemecahan masalah dapat mendorong peserta didik untuk fokus menyelesaikan permasalahan berdasarkan langkah-langkah yang sistematis. Problem solving yang sering didefinisikan sebagai kegiatan formulasi jawaban baru dari aturan-aturan sederhana untuk mencapai tujuan tertentu (Arends, 2012) menuntut peserta didik untuk memahami permasalahan yang diberikan dan berpikir tentang informasi yang dibutuhkan untuk memecahkan masalah tersebut (Sukaisih \& Muhali, 2014) sangat relevan untuk membelajarkan pengetahuan metakognisi.

Hasil penelitian (Mbembok, Fatmawati, \& Adawiyah, 2017) menemukan bahwa penggunaan model pembelajaran berbasis pada pemecahan masalah berdampak positif terhadap kemampuan pemecahan masalah dan hasil belajar kognitif peserta didik. Hasil belajar kognitif dan kemampuan pemecahan masalah berkaitan erat dengan pengetahuan deklaratif seseorang (Asy'ari et al., 2019). Pengetahuan deklaratif yang sering dianggap sebagai pemahaman tentang berpikir atau pengetahuan kognitif dasar peserta didik (Kuhn \& Dean, Jr., 2004) merupakan pengetahuan tentang keterampilan, sumber intelektual, dan kemampuan peserta didik (Schraw et al., 2012) untuk memecahkan masalah yang dihadapi (Yuanita \& Ibrahim, 2018) sangat penting untuk diperhatikan pada awal pembelajaran agar mampu mengkonstruksi strategi-strategi pemecahan secara prosedural berdasarkan situasai masalah yang dihadapi.

Hasil penelitian menunjukkan bahwa pengetahuan prosedural $(0,53)$ dan kondisional $(0,56)$ peserta didik yang berkaitan langsung dengan proses aktualisasi pengetahuan (produk) dalam pemecahan masalah, menjadi indikator pengetahuan metakognisi yang memiliki n-gain yang lebih rendah dibandingkan pengetahuan deklaratif $(0,58)$. Pengetahuan deklaratif merupakan pengetahuan tentang sesuatu (Azevedo \& Aleven, 2013) yang dapat membantu peserta didik untuk mengetahuai factor-faktor yang dapat mempengaruhi proses pembelajaran yang dilakukan mengalami peningkatan setelah pembelajaran. Pengetahuan deklaratif peserta didik tidak cukup untuk memcahkan permasalahan yang bervariasi yang dihadapi peserta didik (Veenman, 2012). Pengetahuan prosedural yang dapat membantu peserta didik dalam penggunaan metode pemecahan masalah (de Backer, Van Keer, \& Valcke, 2012) dan penentuan informasi relevan yang spesifik yang diperlukan untuk pemecahan masalah yang bervariasi (Sugiharto, Corebima, \& Susilo, 2018). Selain itu, pengetahuan kondisional terkait dengan kondisi eksternal yang perlu dipertimbangkan peserta didik agar penggunaan dan efektifitas strategi yang digunakan sesuai dengan konteks permasalahan yang dihadapi 
(Becker et al., 2011) terkait kapan dan dimana pengetahuan yang dimiliki digunakan juga penting untuk dimiliki peserta didik untuk mencapai tujuan pembelajaran secara spesifik.

Prototype buku ajar fisika dasar reflektifintegratif berbasis problem solving sebagai sumber belajar yang digunakan dalam pembelajaran mengintegrasikan atribusi-atribusi untuk menguatkan pengetahuan metakognisi peserta didik melalui, pemberian fenomena konflik kognitif, penyajian permasalahn non-rutin, dan pendalaman materi dengan pemberian fenomena baru baik yang terdapat dalam prototype buku ajar fisika dasar reflektif-integratif berbasis problem solving maupun yang diberikan secara langsung dalam pembelajaran. Sejalan dengan pernyataan tersebut, (Setyowati, Subali, \& Mosik, 2011) menemukan bahwa pendekatan konflik kognitif dengan kegiatan ilmiah dalam pembelajaran fisika mampu menumbuhkan kamampuan berpikir peserta didik, hasil serupa disampaikan (Yuliati et al., 2011) pemberian pertanyaan yang mendorong peserta didik untuk berhipotesis, melakukan penyelidikan, implementasi pengetahuan yang dimiliki, serta menarik kesimpulan dapat menumbuhkembangkan keterampilan berpikir peserta didik. Lebih lanjut (Thomas, 2012) menyatakan bahwa konflik kognitif dan atribusiatribusi yang menantang peserta didik untuk berpikir dapat mempromosikan monitoring pengetahuan dalam proses berpikir dan refleksi pengetahuan awal peserta didik.

\section{SIMPULAN}

Berdasarkan uraian hasil penelitian dan pembahasan dapat disimpulkan bahwa prototipe buku ajar fisika dasar reflektif-integratif berbasis problem solving valid dan efektif untuk meningkatkan pengetahuan metakognisi peserta didik. Penilaian validator terhadap prototype buku ajar fisika dasar reflektif-integratif berbasis problem solving adalah 3,38 (valid) dengan persentase reliabilitas 0,97 (reliabel). Nilai signifikansi pengetahuan metakognisi peserta didik setelah pembelajaran menggunakan prototype buku ajar fisika dasar reflektif-integratif berbasis problem solving adalah $\mathrm{p}<0,05$ (berkategori signifikan). Hasil penelitian ini hanya sebatas pada materi fluida, pengetahuan metakognisi dan pada peserta didik pendidikan fisika FPMIPA IKIP Mataram sehingga penting untuk menghasilkan produk serupa pada materi lain dan pada sampel yang lebih besar serta pada komponen metakognisi lainnya seperti keterampilan dan kesadaran metakognisi (regulasi kognisi) untuk mendapat- kan data yang lebih komprehensif untuk perbaikan pembelajaran secara praktis di dalam kelas dalam upaya membelajarkan kemampuan metakognisi.

\section{UCAPAN TERIMAKASIH}

Ucapan terimakasih disampaikan kepada Kementerian Riset, Teknologi dan Pendidikan Tinggi (Kemristekdikti) atas dukungan dalam menyelesaikan penelitian ini (SK: 7/E/KTP/2019).

\section{DAFTAR PUSTAKA}

Adair, J. (2019). Decision Making and Problem Solving: Break Through Barriers and Banish Uncertainty at Work. Kogan Page Publishers.

Adisendjaja, Y. H. (2008). Analisis buku ajar biologi sma kelas $X$ di Kota Bandung berdasarkan literasi sains. Bandung: Jurusan Pendidikan Biologi Universitas Pendidikan Indonesia.

Adisendjaja, Y. H., \& Romlah, O. (2007). Analisis buku ajar sains berdasarkan literasi ilmiah sebagai dasar untuk memilih buku ajar sains (Biologi). Seminar Pendidikan Nasional Di Jurusan Pendidikan Biologi FMIPA, 25-26.

Arends, R. I. (2012). Learning to teach (9th Editio). New York: The McGraw-Hill Companies, Inc.

Astuti, Y., \& Setiawan, B. (2013). Pengembangan lembar kerja siswa (LKS) berbasis pendekatan inkuiri terbimbing dalam pembelajaran kooperatif pada materi kalor. Jurnal Pendidikan IPA Indonesia, 2(1), 88-92. https://doi.org/10.15294/jpii.v2i1.2515

Asy'ari, M., \& Fitriani, H. (2017). Literatur reviu keterampilan proses sains sebagai dasar pengembangan keterampilan berpikir tingkat tinggi. Prisma Sains: Jurnal Pengkajian Ilmu Dan Pembelajaran Matematika Dan IPA IKIP Mataram, 5(1), 1. https://doi.org/10.33394/j-ps.v5i1.1114

Asy'ari, M., Ikhsan, M., \& Muhali, M. (2018). Validitas instrumen karakterisasi kemampuan metakognisi mahasiswa calon guru fisika. Prisma Sains: Jurnal Pengkajian Ilmu Dan Pembelajaran Matematika Dan IPA IKIP Mataram, 6(1), 18. https://doi.org/10.33394/j-ps.v6i1.955

Asy’ari, M., Ikhsan, M., \& Muhali, M. (2019). 
The effectiveness of inquiry learning model in improving prospective teachers' metacognition knowledge and metacognition awareness. International Journal of Instruction, 12(2), 455-470. https://doi.org/10.29333/iji.2019.12229a

Azevedo, R., \& Aleven, V. (2013). International handbook of metacognition and learning technologies (R. Azevedo \& V. Aleven, Eds.). https://doi.org/10.1007/978-1-44195546-3

Cain, S. E., \& Evans, J. M. (1990). Sciencing: An involvement approach to elementary science methods. Prentice Hall.

de Backer, L., Van Keer, H., \& Valcke, M. (2012). Exploring the potential impact of reciprocal peer tutoring on higher education students' metacognitive knowledge and regulation. Instructional Science, 40(3), 559-588. https://doi.org/10.1007/s11251-011-91905

Dyer, J., Gregersen, H., \& Christensen, C. M. (2011). The innovator's DNA: Mastering the five skills of disruptive innovation. Harvard Business Review Press.

Facione, P., \& Gittens, C. A. (2015). Think critically. Pearson.

Flavell, J. H. (1979). Metacognition and cognitive monitoring: A new area of cognitive-developmental inquiry. American Psychologist, 34(10), 906-911. https://doi.org/10.1037/0003066X.34.10.906

Fraenkel, J. R., Wallen, N. E., \& Hyun, H. H. (2012). How to design and evaluate research in education. Singapore: McGraw-Hill Humanities/Social Sciences/Languages.

Hacker, D. J., Bol, L., \& Keener, M. C. (2008). Metacognition in education: A focus on calibration. Handbook of Metamemory and Memory, 429455.

Hake, R. R. (1999). Analyzing change/Gain scores. Retrieved from http://www.physics.indiana.edu/ sdi/Anal yzingChange-Gain.pdf

Hasanah, U., Gummah, S., \& Herayanti, L. (2018). Perbedaan hasil kemampuan berpikir kritis dan berpikir kreatif siswa menggunakan handout berbasis pemecahan masalah. Prisma Sains : Jurnal
Pengkajian Ilmu Dan Pembelajaran Matematika Dan IPA IKIP Mataram, 6(1), 38. https://doi.org/10.33394/j-ps.v6i1.953

Kuhn, D., \& Dean, Jr., D. (2004). Metacognition: A bridge between cognitive psychology and educational practice. Theory Into Practice, 43(4), 268-273. https://doi.org/10.1207/s15430421tip4304 4

Lester, F. K., Garofalo, J., \& Kroll, D. L. (1989). Self-confidence, interest, beliefs, and metacognition: Key influences on problem-solving behavior. In Affect and Mathematical Problem Solving (pp. 7588). https://doi.org/10.1007/978-1-46123614-6_6

Madsen, A., McKagan, S. B., Martinuk, M. S., Bell, A., \& Sayre, E. C. (2016). Researchbased assessment affordances and constraints: Perceptions of physics faculty. Physical Review Physics Education Research, 12(1), 010115. https://doi.org/10.1103/PhysRevPhysEduc Res.12.010115

Mbembok, R. L., Fatmawati, A., \& Adawiyah, S. R. (2017). Pengaruh model pembelajaran creative problem solving terhadap keterampilan pemecahan masalah dan hasil belajar kognitif siswa. Prisma Sains : Jurnal Pengkajian Ilmu Dan Pembelajaran Matematika Dan IPA IKIP Mataram, 5(1), 25. https://doi.org/10.33394/j-ps.v5i1.1111

Mischel, T. (1971). Piaget: Cognitive conflict and the motivation of thought. Cognitive Development and Epistemology, 311-355.

Muhali, M. (2018). Arah pengembangan pendidikan masa kini menurut perspektif revolusi industri 4.0. Prosiding Seminar Nasional Lembaga Penelitian Dan Pendidikan (LPP) Mandala. Mataram: Mandala Nusra.

National Research Council. (2012). A framework for K-12 science education: Practices, crosscutting concepts, and core ideas. National Academies Press.

Nieveen, N. (1999). Prototyping to reach product quality. In Design Approaches and Tools in Education and Training (pp. 125-135). https://doi.org/10.1007/978-94-011-42557_10

Nitko, A. J., \& Brookhart, S. M. (2011). Educational assessment of students. New 
Jersey: Pearson/Allyn \& Bacon.

Pressley, M., \& Harris, K. R. (2009). Cognitive strategies instruction: From basic research to classroom instruction. Journal of Education, 189(1-2), 77-94. https://doi.org/10.1177/002205740918900 $1-206$

Puspita, L. (2019). Pengembangan modul berbasis keterampilan proses sains sebagai bahan ajar dalam pembelajaran biologi. Jurnal Inovasi Pendidikan IPA, 5(1), 79 88.

https://doi.org/10.21831/jipi.v5i1.22530

Ratumanan, G. T., \& Laurens, T. (2006). Evaluasi hasil yang relevan dengan memecahkan problematika belajar dan mengajar. Bandung: CV Afabeta.

Schraw, G., Crippen, K. J., \& Hartley, K. (2006). Promoting self-regulation in science education: Metacognition as part of a broader perspective on learning. Research in Science Education, 36(1-2), 111-139. https://doi.org/10.1007/s11165-005-39178

Schraw, G., \& Moshman, D. (1995). Metacognitive theories. Educational Psychology Review, 7(4), 351-371. https://doi.org/10.1007/BF02212307

Schraw, G., Olafson, L., Weibel, M., \& Sewing, D. (2012). Metacognitive knowledge and field-based science learning in an outdoor environmental education program. In A. Zohar \& Y. J. Dori (Eds.), Metacognition in Science Education. Contemporary Trends and Issues in Science Education (pp. 57-77). https://doi.org/10.1007/97894-007-2132-6_4

Setyowati, A., Subali, B., \& Mosik, M. (2011). Implementasi pendekatan konflik kognitif dalam pembelajaran fisika untuk menumbuhkan kemampuan berpikir kritis siswa SMP kelas VIII. Jurnal Pendidikan Fisika Indonesia, 7(2). https://doi.org/10.15294/jpfi.v7i2.1078

Sugiharto, B., Corebima, A. D., \& Susilo, H. (2018). A comparison of types of knowledge of cognition of preservice biology teachers. Asia-Pacific Forum on Science Learning \& Teaching, 19(1), 116.

Sukaisih, R., \& Muhali, M. (2014). Meningkatkan kesadaran metakognitif dan hasil belajar siswa melalui penerapan pembelajaran problem solving. Prisma Sains: Jurnal Pengkajian Ilmu Dan Pembelajaran Matematika Dan IPA IKIP Mataram, 2(1), 71. https://doi.org/10.33394/j-ps.v2i1.803

Sutarto, S., \& Indrawati, I. (2010). Diktat media pembelajaran. Jember.

Suyono, S., \& Hariyanto, H. (2011). Belajar dan pembelajaran: Teori dan konsep dasar. Bandung: PT Remaja Rosdakarya.

Taqiyyah, S. A., Subali, B., \& Handayani, L. (2017). Implementasi bahan ajar sains berbahasa Inggris berbasis metakognitif untuk meningkatkan kemampuan pemecahan masalah siswa SMP. Jurnal Inovasi Pendidikan IPA, 3(2), 224. https://doi.org/10.21831/jipi.v3i2.14859

Thomas, G. P. (2012). Metacognition in science education: Past, present and future considerations. In Second International Handbook of Science Education (pp. 131144). https://doi.org/10.1007/978-1-40209041-7_11

Tivani, I., \& Paidi, P. (2016). Pengembangan LKS biologi berbasis masalah untuk meningkatkan kemampuan pemecahan masalah dan karakter peduli lingkungan. Jurnal Inovasi Pendidikan IPA, 2(1), 35. https://doi.org/10.21831/jipi.v2i1.8804

Veenman, M. V. J. (2012). Metacognition in science education: Definitions, constituents, and their intricate relation with cognition. In Metacognition in Science Education. Contemporary Trends and Issues in Science Education (pp. 2136). https://doi.org/10.1007/978-94-0072132-6_2

Wen, Y.-H. (2012). A study on metacognition of college teachers. The Journal of Human Resource and Adult Learning, 8(1), 80.

Westwood, P. S. (2008). What teachers need to know about teaching methods. Victoria: ACER Press.

Yimer, A., \& Ellerton, N. F. (2010). A five-phase model for mathematical problem solving: Identifying synergies in pre-serviceteachers' metacognitive and cognitive actions. ZDM, 42(2), 245-261. https://doi.org/10.1007/s11858-009-02233

Yuanita, L., \& Ibrahim, M. (2018). Pengembangan model pembelajaran 
Jurnal Inovasi Pendidikan IPA, 5 (2), 2019 - 215

Muhammad Asy'ari, Samsun Hidayat, Muhali Muhali

reflektif-metakognitif untuk meningkatkan kemampuan metakognisi siswa SMA

(Universitas Negeri Surabaya). https://doi.org/10.13140/RG.2.2.14759.19 361

Yuliati, D. I., Yulianti, D., \& Khanafiyah, S. (2011). Pembelajaran fisika berbasis hands on activities untuk menumbuhkan kemampuan berpikir kritis dan meningkatkan hasil belajar siswa SMP. Jurnal Pendidikan Fisika Indonesia, 7(1). https://doi.org/10.15294/jpfi.v7i1.1064

Zohar, A., \& Dori, Y. J. (2011). Metacognition in science education: Trends in current research (Vol. 40). Springer Science \& Business Media. 